\title{
Valores Organizacionais Declarados e Praticados na Universidade Federal de Santa Catarina
}

\author{
Declared and Practiced Organizational Values at Federal University of Santa Catarina
}

Valores Organizacionales Declarados y Practicados en la Universidad Federal de Santa Catarina

Thiago Soares Nunes

Pós-Doutorado em Administração pela Universidade Estadual de Maringá (UEM) Pesquisador do Núcleo de Estudos de Processos Psicossociais e de Saúde nas Organizações e no Trabalho (NEPPOT/UFSC) http://lattes.cnpq.br/3796147728637598 http://orcid.org/0000-0002-1323-8160

adm.thiagosn@gmail.com

Suzana da Rosa Tolfo

Doutora em Administração pela Universidade Federal de Rio Grande do Sul (UFRGS)

Professora do Programa de Graduação e Pós-Graduação em Psicologia e do Programa de Pós-Graduação em Administração da Universidade Federal de

Santa Catarina (UFSC)

http://lattes.cnpq.br/2639021733757849

https://orcid.org/0000-0002-6321-6496

srtolfo14@gmail.com

Ivonete Steinbach Garcia Doutora em Psicologia Organizacional e do Trabalho pela Universidade Federal de Santa Catarina (UFSC) Professora na UNISOCIESC/FGV em cursos de graduação e pós-graduação http://lattes.cnpq.br/1019515549542348 https://orcid.org/0000-0001-8442-1862 ivonetesteinbach@uol.com.br

Resumo: Os valores organizacionais representam princípios e crenças que norteiam a vida das pessoas na organização. Este artigo objetiva descrever a percepção de servidores docentes e técnico-administrativos em relação aos valores organizacionais declarados e praticados na Universidade Federal de Santa Catarina. Os procedimentos desta pesquisa privilegiaram o método misto, a perspectiva descritiva e o estudo de caso, com aplicação de questionário online para coleta (214 respostas) e a utilização de estatística descritiva e análise conteúdo. Constatou-se que os valores mais praticados na Universidade estudada são aqueles relativos ao ensino (internacionalizada; acadêmica e de qualidade; culta; atuante), que tem relação com os discentes, são os mais praticados dentro da Universidade. Porém, os participantes afirmam que a maioria dos valores declarados são menos praticados. Identificou-se incongruências entre os valores declarados e praticados que limitam as práticas, como: excesso de burocracia, falta de interesse da gestão, má administração, política, corporativismo, falta de ética, e outros. Estes elementos fazem com que os trabalhadores tenham dificuldades para se identificar com os valores organizacionais.

Palavras-chave: Valores; Cultura organizacional; Universidade; Setor público; Servidores públicos federais.
Abstract: Organizational values represent principles and beliefs that guide the life of people in the organization. This article aims to describe the perception of teachers and technicians in administration, which are both public servants, in relation to the organizational values of the Federa University of Santa Catarina. The procedures of this research privileged the mixed method, the descriptive perspective, and case study, with the application of an online questionnaire for data collection (214 responses) and the use of descriptive statistics and content analysis. It was found that the values most practiced in the studied University are the ones related to teaching (internationalized, academic and quality, cultured, active), more related to the students. However, participants state that most declared values are less practiced. We identified inconsistencies between the declared and practiced values. Excessive bureaucracy, lack of management interest, mismanagement, politics, corporatism, lack of ethics are some of the factors that restrain the actual practice of the values, and they are the reason why servants find it hard to identify with organizational values.

Keywords: Values; Organizational culture University; Public sector; Public federal servants.
Resumen: Los valores organizacionales representan principios y creencias que guían la vida de las personas en la organización. Este artículo objetiva describir la percepción de servidores docentes y técnico-administrativos en relación a los valores organizacionales declarados y practicados en la Universidad Federal de Santa Catarina. Los procedimientos de esta investigación privilegiaron el método mixto, la perspectiva descriptiva y el estudio de caso, con aplicación de cuestionario online para recolección (214 respuestas) y la utilización de estadística descriptiva y análisis de contenido. Se constató que los valores más practicados en la Universidad estudiada son aquellos relativos a la enseñanza (internacionalización, académica y de calidad, culto, actuante), que tiene relación con los discentes, son los más practicados dentro de la Universidad. Sin embargo, los participantes afirman que la mayoría de los valores declarados son menos practicados. Se identificaron incongruencias entre los valores declarados y practicados que limitan las prácticas, como: exceso de burocracia, falta de interés de la gestión, mala administración, política, corporativismo, falta de ética, y otros. Estos elementos hacen que los trabajadores tengan dificultades para identificarse con los valores organizacionales.

Palabras clave: Valores; Cultura organizacional Universidad; Sector público; Servidores públicos federales.

\section{INTRODUÇÃO}

"O que são valores?" Gouvêa (2008) afirma que tal fenômeno está relacionado à valoração de modo geral, algo que antecede a pesquisa científica acerca dos valores pessoais, culturais ou organizacionais. O autor identifica valores humanos, valores pessoais e valores compartilhados, valores do trabalho, valores de família, valores éticos, valores religiosos, dentre outros. Ressalta, ainda, a necessidade de distinguir melhor o significado do conceito, de modo a contribuir para que se possa conferir maior precisão à sua utilização nos discursos científicos. Isso remete aos 
pesquisadores a indagarem: $O$ que define valores em diferenciação a outros construtos relativos às organizações? Os valores estão entre os componentes da cultura organizacional?

Especificamente no âmbito do trabalho, enquanto categoria central na sociedade em que vivemos, identifica-se uma inquietação dos pesquisadores de áreas como a Psicologia e a Administração, para a necessidade de compreender os comportamentos das pessoas nas organizações, o que reverbera no aumento do número de pesquisas voltadas para a temática dos valores organizacionais. De acordo com Porto e Pilati (2010), diversos modelos teóricos sobre valores do trabalho são encontrados na literatura, mas somente a partir de 1990 surgiram esforços para compreender esta temática, a partir de teorias sobre valores gerais. Em pesquisa realizada por Nascimento, Adaid-Castro, Carvalho e Demo (2016) em periódicos científicos da área de Administração (com classificação igual ou superior a B2), no período entre 2000 a 2013, foram identificados 56 artigos sobre valores organizacionais. Para os autores, a quantidade de trabalhos é limitada, se considerada a importância do tema para as organizações.

Os valores organizacionais compõem um conjunto específico no universo dos valores humanos e fazem alusão especificamente às organizações. Os valores organizacionais representam princípios e crenças que norteiam a vida das pessoas e da "organização", e estão a serviço de interesses tanto individuais quanto coletivos (Tamayo, 1996). Tanto pessoas quanto organizações, por meio de seus gestores, necessitam de objetivos para atribuir significado àquilo que fazem e alcançar resultados. Hofstede (1980) assevera que o sistema de valores é responsável pela "programação mental" das pessoas, uma vez que constitui a centralidade da cultura organizacional e é orientador de comportamentos. Tamayo (2006) afirma que os valores constituem o núcleo fundamental da cultura organizacional. O estudo desse fenômeno é de grande relevância, tanto na área de pesquisa acadêmica, quanto no escopo do diagnóstico e da gestão organizacional, pois, de acordo com Tamayo (2007), é por meio dos valores que as pessoas nas organizações expressam seus objetivos.

Ao se considerar a importância de compartilhamento dos valores organizacionais, também se mostra necessário o alinhamento desses valores aos dos trabalhadores e vice-versa. Tamayo (2007, p. 20) ressalta que o trabalho tem que estar alinhado às metas do trabalhador e afirma que "os valores têm um papel dominante no comportamento do trabalhador e nas suas atitudes e reações no trabalho". Porém, de maneira paradoxal, em meio às transformações no mundo do trabalho, cada vez mais os trabalhadores são convidados a "vestir a camisa da empresa", como prova de dedicação e comprometimento, mas a mensagem subliminar das organizações em alguns momentos parece favorecer a ideia de exclusividade na dimensão unilateral, pois 0 compromisso deveria ser mútuo, entre organização e trabalhadores e trabalhadores e organização.

Os valores são construídos com base na confiabilidade e credibilidade. Entretanto, algumas organizações expressam valores relacionados ao bem-estar e crescimento de seus trabalhadores, mas possuem políticas de gestão contrárias aos valores declarados, podendo gerar implicações nas suas relações.

Portanto, este artigo tem por objetivo descrever a percepção de servidores docentes e técnico-administrativos em relação aos valores organizacionais declarados e praticados na Universidade Federal de Santa Catarina.

A pesquisa justifica-se pela necessidade de aprofundar um importante elemento da cultura organizacional, os valores organizacionais, neste caso, da Universidade analisada. Portanto, no decorrer do trabalho, são identificados os valores declarados, praticados ou não pela organização e seus trabalhadores, as razões pelo não cumprimento destes, e a identificação dos trabalhadores com os valores declarados. Com isso é possível verificar práticas (negativas) que (impedem o bom funcionamento) que vão de encontro a estes valores, as quais influenciam nas relações interpessoais e no desempenho da universidade. Elementos estes identificados, que estão presentes no próprio serviço público brasileiro e nas organizações públicas.

A partir do exposto, o artigo encontra-se estruturado de modo a apresentar uma breve abordagem sobre os valores organizacionais, entendido como parte da cultura organizacional, além da descrição dos procedimentos metodológicos adotados para a pesquisa, e a discussão dos resultados obtidos. Ao seu final, são tecidas as considerações acerca dos principais achados no estudo, destacando ainda as limitações da mesma.

\section{VALORES E CULTURA ORGANIZACIONAL}

As pesquisas em cultura organizacional têm sido objeto de uma multiplicidade de abordagens teóricas e metodológicas, que ora se assemelham, ou se completam, ora se excluem mutuamente. Em uma concepção de base antropológica, o conceito de cultura enfoca os aspectos simbólicos que permeiam os processos de interação humana; na perspectiva sociológica, a ênfase recai sobre o processo de elaboração do universo simbólico ou da construção da realidade de determinado agrupamento social e, os estudos de base psicológica, reconhecem a variação cultural em organizações e/ou grupos e entendem que a cultura só poderá ser transmitida e consolidada por meio das pessoas (Silva \& Zanelli, 2004).

Para Smircich (1983) as diferentes correntes teóricas sobre cultura organizacional se dividem basicamente em duas, as quais enfatizam determinada relação entre organização e cultura, de acordo com suas bases epistemológicas. Nesta subdivisão, uma relaciona cultura como algo que a organização tem, e a segunda como algo que a organização é. Os adeptos da primeira linha reconhecem que as organizações produzem traços culturais mais ou menos distintos, tais como valores, normas, rituais, cerimônias e expressões verbais e consideram que a cultura produz um senso de identidade aos membros da organização. Isso, de acordo com Ferreira e Assmar (1999), assegura a estabilidade dos sistemas e serve como instrumento de orientação e modelagem do comportamento. Já os favoráveis à segunda perspectiva, abordam as organizações como se elas fossem a cultura e analisam os seus 
aspectos expressivos, ideacionais e simbólicos, ao ressaltar os valores, símbolos e significados compartilhados.

Representante da segunda perspectiva, e um dos autores mais reconhecidos no âmbito internacional da cultura organizacional, conceitualmente e metodologicamente, é Edgar Schein (Fleury, 1987; Fleury, 1996; Freitas, 2007). Para Schein (2009, p. 16) a cultura organizacional é definida como

[...] um padrão de suposições básicas compartilhadas, que foi aprendido por um grupo à medida que solucionava seus problemas de adaptação externa e integração interna. Esse padrão tem funcionado bem o suficiente para ser considerado válido, e, por conseguinte, para ser ensinado aos novos membros como o modo correto de perceber, pensar e sentir-se em relação a esses problemas.

No modelo teórico de Schein $(2001 ; 2009)$, são propostos três níveis de elementos culturais, os quais variam de acordo como grau de acessibilidade: os artefatos, os valores declarados e os pressupostos básicos. No nível mais superficial e aparente de análise encontram-se os artefatos visíveis, que correspondem ao ambiente físico da organização, arquitetura, tecnologia, tipos de vestuário, padrões visíveis e audíveis de comportamento, documentos públicos, como material para orientação dos funcionários, nos quais podem ser identificados valores idealizados e crenças, além dos rituais e mitos organizacionais (Schein, 2009).

Em um nível intermediário, encontram-se os valores declarados, que embasam as estratégias, metas e filosofias organizacionais e, em geral funcionam como justificativas para os comportamentos esperados, mas que ainda não são sistematicamente praticados. Segundo Silva e Zanelli (2004), se esses valores forem compartilhados e praticados nas relações de trabalho dentro e fora da organização, eles se tornarão arraigados. Domenico e Latorre (2008) corroboram e enfatizam que um valor se torna pressuposto básico somente quando é validado socialmente pelos membros da organização, ao perceberem que sua utilização serve para obter consistentemente resultados positivos. Por fim, no nível mais profundo e de difícil acesso, encontram-se os pressupostos básicos, que se referem ao que é inconsciente, verdade inquestionável e natural na organização, resultado de respostas aprendidas pelas pessoas e associadas a comportamentos para solucionar problemas.

Schein (2009) postula que se as crenças e os valores assumidos estiverem congruentes com as percepções básicas, a articulação desses valores em uma filosofia de operação pode ser útil para unir o grupo, servindo como fonte de identidade e missão central. Em consonância com esta perspectiva, entende-se que na análise de crenças e valores organizacionais, deve-se abstrair o que é congruente com as suposições básicas e o que são racionalizações, ou somente anseios para o futuro. As crenças e valores tendem a ser obtidos quando se questiona sobre o comportamento observado, ou outros artefatos que impressionam alguém pelo caráter enigmático, anômalo ou inconsciente. Como a essência da cultura está no padrão de suposições básicas prevalecentes, quando alguém as decifra, é possível entender os níveis mais superficiais e lidar com eles de maneira apropriada. Ao definir os elementos básicos da cultura organizacional, Silva, Zanelli e Tolfo (2013) afirmam que representa o modo como de fazer as coisas naquela organização, que configura um jeito típico de ser e de agir de determinada comunidade humana singular e que pelo histórico de bons resultados gerou uma identidade compartilhada Tolfo, Silva e Krawulski (2013) salientam que a cultura nas organizações também pode ser abordada como um sistema simbólico, que contempla comportamentos, valores, normas, ritos e mitos, comunicação, e diversos outros elementos culturais (Freitas, 2007) voltados para compreensões compartilhadas sobre os significados do que ocorre com os participantes da organização. Constitui-se em meio de legitimar a construção social das organizações aos seus membros (Geertz, 1989). Para compreender o conjunto da cultura, em sua lógica material e psicossocial interna, é mister conhecer seus costumes, práticas, concepções e transformações pelas ocorridas e que conferem sentido para seus membros (Santos, 2004). Silva e Silva (2010) defendem que estudar a cultura, em especial os valores organizacionais, possibilita entender a maneira singular como as pessoas se relacionam com os ambientes externo e interno, e consciente e inconsciente (simbólicos).

Os valores são o aspecto central de cultura organizacional, importantes para o sucesso da organização e devem ser considerados como elementos norteadores para o comportamento organizacional no dia-a-dia (Freitas, 1991; 2007). De acordo com Demo, Fernandes e Fogaça (2017), os valores têm como função orientar a organização e guiar comportamentos que são de extrema importância para o dia-a-dia da empresa. Schein (2001; 2009) revela que os valores expressam a cultura manifesta das organizações que consiste de elementos compartilhados, que constituem os padrões para perceber, pensar, sentir e, sobretudo, agir, orientando tanto os comportamentos individuais das pessoas, quanto as interações humanas coletivas no âmbito da organização. Os valores organizacionais podem ainda ser definidos como princípios conquistados e organizados em ordem de importância, referindo-se ao que é central e o que é periférico no contexto organizacional, ou ao que é desejável ou indesejável.

Para Katz e Kahn (1974) os valores representam um elemento integrador, na medida em que são compartilhados pelos membros da organização. As organizações que desconsideram a análise dos valores e se baseiam exclusivamente no papel prescrito possuem uma estrutura frágil e inibem comportamentos de criatividade e inovação, os quais podem ser considerados condição sine qua non para a sobrevivência das organizações, bem como para a obtenção de um desempenho elevado. $\mathrm{O}$ alinhamento e compartilhamento dos valores influenciam diversos resultados organizacionais, dentre eles de desempenho e satisfação (Zanelli \& Silva, 2008).

Os valores possuem forte presença nas normas organizacionais, as quais refletem em comportamentos observáveis (Hogan \& Coote, 2014). Para os autores, é por meio das normativas organizacionais que os valores são obtidos, transmitidos e vivenciados no meio social/laboral.

Zanelli e Silva (2008) esclarecem ainda que os valores organizacionais podem ser classificados em dois tipos: valores arraigados e valores declarados. Os valores arraigados são 
relativamente estáveis e duradouros e, neste caso, pensamentos, sentimentos e ações mantêm congruência e integração, mesmo que nem sempre seja lógico para o observador. Os valores declarados, por sua vez, são pouco estáveis e representam idealizações ou racionalizações sobre o que é apreciado ou considerado desejável. Mas, se os valores declarados forem vivenciados ao longo do tempo, poderão vir a ser arraigados. Para Silva e Silva (2010), os valores declarados orientam o alcance dos objetivos organizacionais e o direcionamento que as organizações almejam acerca do comportamento das pessoas. Também determinam orientação, vínculo e o comprometimento dos colaboradores com a organização. Teixeira (2008) anuncia que os valores declarados, publicamente anunciados, podem ou não ser compartilhados e o seu anúncio pode destinar-se a aumentar a reputação organizacional.

De forma a ilustrar os valores declarados da Universidade Federal de Santa Catarina (UFSC), publicados nos documentos e nos meios de comunicação, universo de estudo deste trabalho, apresenta-se os mesmos a seguir:

- Acadêmica e de Qualidade: busca contínua de patamares de excelência acadêmica, em todas as suas áreas de atuação, em especial no ensino, pesquisa e extensão;

- Ousada: capaz de identificar e optar por novos caminhos e de criar novas oportunidades, carreiras e práticas em conformidade com uma visão inovadora

- Culta: criadora e irradiadora de arte e ciência;

- Atuante: capaz de opinar, influenciar e propor soluções para grandes temas, tais como: acesso ao conhecimento e à cidadania, desenvolvimento científico e tecnológico, violência urbana, sustentabilidade ambiental e desigualdade social, entre outros;

- Internacionalizada: capaz de intensificar parcerias e convênios com instituições internacionais, contribuindo para o seu desenvolvimento, o do Brasil e o de outras nações;

- Livre: uma Instituição com servidores docentes e técnicoadministrativos e estudantes livres para desenvolver suas convicções e suas vocações no ensino, na pesquisa e na extensão;

- Autônoma: capaz de decidir sobre seus próprios rumos;

- Democrática e Plural: assegura o reconhecimento pleno de sua diversidade e autodeterminação de seus vários segmentos;

- Bem Administrada e Planejada: com estratégias eficientes e efetivas de gestão e de busca dos recursos para a realização de suas metas;

- Saudável: ancorada na concepção de que a saúde é construída e vivida pelas pessoas em seu ambiente cotidiano, contribuindo para uma formação integral e maior qualidade de vida;

- Responsável: orientada pela responsabilidade ética, social e ambiental (UFSC, 2010).

Tamayo e Borges (2006) compreendem que a percepção dos valores organizacionais é resultado tanto do que é transmitido por meio de documentos oficiais da empresa e do discurso oficial dos gestores, quanto das práticas adotadas, das atitudes dos dirigentes e dos pares e de tudo aquilo que ocorre no cotidiano da organização. Essa aproximação permite que se estudem os valores organizacionais a partir da representação mental que os atores sociais têm do sistema axiológico da empresa. Entende-se que a realidade social é construída e representada por meio das percepções das pessoas, em que cada membro assume o papel ativo na construção dessa realidade, por meio dos esquemas interpretativos.

Se os valores declarados e praticados forem percebidos como incongruentes, os comportamentos dos colaboradores tendem a ser incompatíveis com os valores declarados na organização. Se houver a coerência na disseminação dos valores com a prática, os colaboradores passam a confiar nos valores declarados; caso contrário, a percepção de incongruência passa a ser desfavorável para o alcance dos objetivos organizacionais (Silva \& Silva, 2010). Ou seja, os valores compartilhados tornam a cultura mais forte, uma vez que se os valores declarados são praticados, provavelmente os trabalhadores tomarão decisões apoiadas nestes padrões (Deal \& Kennedy, 2000). E, desta forma, a vida organizacional tem maior significado para os trabalhadores, e, a partir disso, se consideram como parte importante de organização (Siqueira \& Vieira, 2012).

Por fim, os valores em seus diferentes níveis de profundidade, são considerados elementos-chave da cultura organizacional e se constituem em possíveis indicadores da confiança organizacional.

\section{MÉTODO}

Esta pesquisa privilegiou o método misto, que compreende uma abordagem de investigação combinada de estratégias quantitativas e qualitativas na coleta e análise dos dados em um único estudo (Creswell, 2007). A pesquisa quantitativa, tem a intenção de garantir maior precisão aos resultados, evitando, assim, distorções de análise e interpretação, ao possibilitar, consequentemente, uma margem de segurança quanto às inferências (Richardson, 2008). Por sua vez, a pesquisa qualitativa visa responder questões com um grau de realidade que não pode ser quantificado, trabalhando com um universo de significados, motivos, aspirações, valores e atitudes que correspondem a um espaço mais profundo das relações, dos processos e dos fenômenos (Minayo, 1994). Ou seja, a utilização de uma abordagem quantitativa tem por objetivo apresentar dados estatísticos descritivos sobre o fenômeno estudado, valores organizacionais, de modo a permitir uma demonstração mais abrangente. Com isso, a abordagem qualitativa visa complementar estas informações por meio de verbalizações com significados e motivos apresentados pelos participantes, os quais não podem ser reduzidos à operacionalização de variáveis.

A presente pesquisa se caracteriza como um estudo de caso, cujo lócus foi a Universidade Federal de Santa Catarina. O estudo de caso é caracterizado por revelar a multiplicidade de dimensões em uma determinada situação ou problema, focalizando-o como um todo (Ludke \& André, 1986). Outra característica deste estudo reside no fato do mesmo ser do tipo descritivo, pois intenciona conhecer a natureza do problema de pesquisa para então permitir a descrição de suas características. Gil (2007) destaca que essa modalidade de pesquisa tem como principal objetivo descrever características de determinada população ou fenômeno ou, ainda, o estabelecimento de relações entre variáveis. 
Até 2014 a UFSC contabilizava aproximadamente 2.540 servidores docentes (ensino superior, educação básica, e substitutos) e 3.174 servidores técnico-administrativos (UFSC, 2014), portanto, a população envolvida na pesquisa foi composta por 5.714 servidores ativos. Optou-se por não definir uma amostra nesta investigação uma vez que os pesquisadores tiveram meios para divulgar e enviar a pesquisa a toda a população. Deste modo, a mesma pode ser considerada censitária, uma vez que abrange a totalidade dos componentes do universo (Marconi \& Lakatos, 2009). Embora os pesquisadores tivessem acesso a população da pesquisa, não se conseguiu atingir sua totalidade. Assim, 214 servidores responderam ao questionário, sendo, $54,2 \%$ técnicosadministrativos e $45,8 \%$ docentes.

Os dados foram coletados mediante a aplicação de um questionário online, que passou por um pré-teste com docentes, técnicos-administrativos e pós-graduandos com conhecimento sobre o tema. Dessa forma, foi possível revisar e direcionar aspectos da investigação a partir das experiências destes sujeitos. O questionário foi divulgado pelo setor de divulgação da Universidade e por e-mails dos servidores coletados nos sites dos cursos, departamentos, centros, secretarias e demais setores. Os dados quantitativos (questões fechadas) e qualitativos (questões abertas) foram coletados concomitantemente. Os procedimentos concomitantes, segundo Creswell (2007), possibilitam ao pesquisador convergir os dados quantitativos e qualitativos de modo a obter uma análise mais ampla do objetivo/problema da pesquisa. $O$ instrumento online inclui, inicialmente, questionamentos sobre dados demográficos dos participantes e do seu vínculo com a organização. Já com relação ao foco da pesquisa, os valores organizacionais da UFSC, os mesmos foram identificados nos documentos oficiais e site institucional, redigidos em perguntas para verificar se estes são ou não praticados (questionamento fechado), e, com isso, as questões seguintes (abertas) indagaram sobre as razões de não cumprimento dos valores, e a identificação do trabalhador com os mesmos. A utilização de um instrumento online facilitou o acesso aos participantes, bem como permitiu o completo anonimato - uma vez que não foi solicitado identificação.

A partir da coleta dos dados do questionário online, foi realizada a análise e interpretação dos mesmos. Os dados das questões fechadas foram analisados seguindo uma abordagem de análise quantitativa, com a utilização de estatística descritiva. Portanto, foi utilizado o programa Statistical Package for the Social Sciences (SPSS) para realizar uma análise descritiva de distribuição de frequência com o intuito de identificar se os valores declarados da UFSC eram praticados ou não. Por sua vez, a análise dos questionamentos abertos foi em conformidade com a abordagem de análise qualitativa, com a utilização da análise de conteúdo. Esta consiste em um conjunto de técnicas de análise das comunicações com o objetivo de obter indicadores por meio de procedimentos sistemáticos e objetivos de descrição do conteúdo das mensagens para a inferência de conhecimento referente às condições de geração dessas mensagens (Bardin, 2004). Portanto, durante a análise, foram desenvolvidas as seguintes etapas conforme a autora apresenta: pré-análise; exploração do material e o tratamento dos resultados; inferência e interpretação.

Deste modo, foram criadas e recriadas categoria, subcategorias e elementos de análises a partir dos dados obtidos, conforme pode ser visualizado no Quadro 1 a seguir. A subcategoria Práticas fo construída com os dados quantitativos e qualitativos, por sua vez, a subcategoria Identificação com os valores, com os dados qualitativos.

Quadro 1: Categoria e subcategorias de análise

\begin{tabular}{|c|c|c|}
\hline CATEGORIA & SUBCATEGORIAS & $\begin{array}{l}\text { ELEMENTOS } \\
\text { DE ANÁLISE }\end{array}$ \\
\hline $\begin{array}{l}\text { Valores } \\
\text { Organizacionais } \\
\text { (Conjunto de } \\
\text { características } \\
\text { que orientam a } \\
\text { forma, }\end{array}$ & $\begin{array}{l}\text { Práticas } \\
\text { (Percepção dos } \\
\text { participantes sobre a } \\
\text { prática ou não } \\
\text { prática dos valores } \\
\text { declarados pela } \\
\text { Universidade). }\end{array}$ & $\begin{array}{l}\text { 1. Execução ou } \\
\text { cumprimento } \\
\text { 2. Razões de } \\
\text { descumprimento } \\
\text { 3. Inter-relação } \\
\text { discurso-prática }\end{array}$ \\
\hline $\begin{array}{l}\text { comportamento, } \\
\text { ações dos } \\
\text { indivíduos ou da } \\
\text { Universidade na } \\
\text { sua relação com } \\
\text { os outros.) }\end{array}$ & $\begin{array}{l}\text { Identificação com } \\
\text { os valores } \\
\text { (Identificação dos } \\
\text { participantes com os } \\
\text { valores formais, } \\
\text { apresentados pela } \\
\text { Universidade) }\end{array}$ & $\begin{array}{l}\text { 1. Interesses } \\
\text { próprios } \\
\text { 2. Obstáculos }\end{array}$ \\
\hline
\end{tabular}

Fonte: elaborado pelos autores

Para garantir o anonimato dos participantes da pesquisa, os respondentes foram identificados com a letra "P" seguidos com seus respectivos números ( 1 a 214).

\section{ANÁLISE E INTERPRETAÇÃO DOS DADOS}

Em relação aos participantes da pesquisa, alguns dados sobressaem. No aspecto de gênero, o público feminino teve 53,3\% de participação na pesquisa, o que corresponde a 114 respostas, 15 a mais do que o sexo masculino. $\mathrm{Na}$ faixa etária, a grande maioria dos participantes $(41,1 \%$ ou 88 respondentes) têm idade entre 25 e 35 anos, e quanto ao tempo de serviço, 49,5\% (106) estão na Universidade entre 1 a 5 anos, ou seja, representam os trabalhadores que entraram relativamente há pouco tempo na organização. Em relação à formação, 82,2\% (176) têm curso de pós-graduação completo, o que representa uma alta qualificação dos trabalhadores. A maioria dos respondentes da pesquisa (116 ou $54,2 \%$ ) são servidores técnico-administrativos. O regime de trabalho com maior incidência é o de 40 horas semanais, com 50,9\% (109), seguido por Dedicação Exclusiva com 43,9\% (94). Quanto à ocupação ou não de cargo de direção ou função gratificada $80,8 \%$ (173) dos respondentes afirmaram que não possuem.

Os valores organizacionais compreendem um conjunto de características que orientam o comportamento e as ações dos indivíduos e da organização na sua relação com os outros e com o meio. Eles se desenvolvem em interações com as necessidades e exigências internas e externas da organização (Tamayo \& Borges, 2006). Portanto, nesta seção são destacados os valores que a organização explicita, suas consistências e inconsistências a partir de duas subcategorias: prática dos valores organizacionais e identificação com os valores organizacionais. 


\subsection{Prática dos valores organizacionais}

Nesta subcategoria são apresentadas as percepções dos participantes sobre a prática ou não prática dos valores esposados (declarados) pela organização, bem como os motivos de descumprimento, e a inter-relação entre o discurso e a prática. Os valores são um dos aspectos centrais de cultura organizacional, importantes para o sucesso da organização e devem (ou deveriam) ser considerados como elementos norteadores para 0 comportamento organizacional no cotidiano (Freitas, 2007). Do mesmo modo que os valores singulares orientam os comportamentos e práticas dos indivíduos em suas vidas, os valores organizacionais, segundo Tamayo (1996), norteiam a vida dentro da organização, sustentando e orientando as atitudes e comportamentos no ambiente laboral. De acordo com Tamayo (1996) e Tamayo e Borges (2006), os valores organizacionais são como princípios ou crenças, relativos a comportamentos ou metas organizacionais desejáveis que orientam a vida da organização e estão a serviço de interesses individuais, coletivos ou mistos.

Com vistas a identificar os valores propagados e "testados" ao longo do tempo e validados socialmente pelos membros da organização pesquisada, primeiramente foram identificados os 11 valores que a própria organização tem formulado no momento da pesquisa, e, a partir disto, foi questionado aos participantes se tais valores são praticados ou não praticados, conforme pode ser visualizado na Tabela 1.

Tabela 1: Valores organizacionais: valores declarados

\begin{tabular}{|c|c|c|c|c|c|}
\hline VALORES DECLARADOS & & EM BRANCO & NÃO PRATICADO & PRATICADO & TOTAL \\
\hline \multirow{2}{*}{ ACADÊMICA E DE QUALIDADE } & Freq. & 4 & 44 & 166 & 214 \\
\hline & $\%$ & 1,9 & 20,6 & 77,6 & 100,0 \\
\hline \multirow{2}{*}{ ATUANTE } & Freq. & 4 & 89 & 121 & 214 \\
\hline & $\%$ & 1,9 & 41,6 & 56,5 & 100,0 \\
\hline \multirow{2}{*}{ AUTÔNOMA } & Freq. & 4 & 130 & 80 & 214 \\
\hline & $\%$ & 1,9 & 60,7 & 37,4 & 100,0 \\
\hline \multirow{2}{*}{ BEM ADMINISTRADA E PLANEJADA } & Freq. & 4 & 175 & 35 & 214 \\
\hline & $\%$ & 1,9 & 81,8 & 16,4 & 100,0 \\
\hline \multirow{2}{*}{ CULTA } & Freq. & 4 & 79 & 131 & 214 \\
\hline & $\%$ & 1,9 & 36,9 & 61,2 & 100,0 \\
\hline \multirow{2}{*}{ DEMOCRÁTICA E PLURAL } & Freq. & 4 & 107 & 103 & 214 \\
\hline & $\%$ & 1,9 & 50,0 & 48,1 & 100,0 \\
\hline \multirow{2}{*}{ INTERNACIONALIZADA } & Freq. & 4 & 42 & 168 & 214 \\
\hline & $\%$ & 1,9 & 19,6 & 78,5 & 100,0 \\
\hline \multirow{2}{*}{ LIVRE } & Freq. & 5 & 120 & 89 & 214 \\
\hline & $\%$ & 2,3 & 56,1 & 41,6 & 100,0 \\
\hline \multirow{2}{*}{ OUSADA } & Freq. & 4 & 128 & 82 & 214 \\
\hline & $\%$ & 1,9 & 59,8 & 38,3 & 100,0 \\
\hline \multirow{2}{*}{ SAUDÁVEL } & Freq. & 4 & 159 & 51 & 214 \\
\hline & $\%$ & 1,9 & 74,3 & 23,8 & 100,0 \\
\hline \multirow{2}{*}{ RESPONSÁVEL } & Freq. & 4 & 110 & 100 & 214 \\
\hline & $\%$ & 1,9 & 51,4 & 46,7 & 100,0 \\
\hline
\end{tabular}

Fonte: dados primários

A UFSC tem por valor principal se firmar cada vez mais como um centro de excelência acadêmica, em âmbito regional, nacional e internacional, e assim contribuir para a construção de uma sociedade justa e democrática (UFSC, 2010). E para alcançar isso ela se baseia nos valores listados na tabela anterior.

Dentre os 11 valores listados, os mais praticados, segundo os participantes, foram: internacionalizada $(78,5 \%)$; acadêmica e de qualidade $(77,6 \%)$; culta $(61,2 \%)$; e atuante $(56,5 \%)$. Estes valores estão ligados intensamente com o objetivo principal da organização, o ensino e a pós-graduação, no caso do mais frequente.

Em sequência são apresentadas respostas com base nas questões abertas do questionário e que trazem os conteúdos provenientes das falas dos participantes. Quanto ao questionamento geral sobre os valores da UFSC, as respostas predominantes estão apresentadas a seguir: "[Vejo a UFSC] como uma instituição reconhecida pela qualidade e indicadores de produção" (P3); "Hoje destaca-se nas mais diversas áreas de ensino e pesquisa" (P90); "Hoje, percebo que, cada vez mais, as pessoas engajam-se na realização de um trabalho com excelência, buscando elevar o ranking da UFSC para uma das melhores universidades no contexto nacional" (P211).

Foi evidenciado que os valores intimamente ligados ao ensino, que têm relação com os discentes, são os mais identificados como praticados dentro da Universidade. Estes valores, segundo os participantes, apresentam uma prática mais evidenciada e de maior qualidade, ao contrário dos valores e práticas que são voltados ao ambiente e trabalho interno da instituição. As universidades, por missão ou objetivo, devem ser orientadas para os usuários, ou seja, 
buscam promover a formação do cidadão para atuação no mercado de trabalho (Baldridge, 1982; Finger, 1988). Considera-se, ainda, que um valor torna-se pressuposto básico somente quando é validado socialmente pelos membros da organização, tornando-se valores arraigados quando forem compartilhados e praticados nas relações de trabalho dentro e fora da organização (Dominico \& Latorre, 2008).

Por sua vez, a maior parte dos valores declarados da Universidade, segundo os participantes da pesquisa, são menos praticados. Em ordem crescente de frequência, democrática e plural (50\%), responsável $(51,4 \%)$, livre $(56,1 \%)$, ousada $(59,8 \%)$, autônoma $(60,7 \%)$, saudável $(74,3 \%)$, bem administrada e planejada $(81,8 \%)$. Os dois primeiros não apresentam uma variação muito grande, porém são fundamentais para o convívio entre os trabalhadores e a execução do trabalho, pois tratam de aspectos como respeito à cidadania e a responsabilidade ética, social e ambiental.

Os valores livre e ousada têm diferença um pouco maior, e estão presentes em muitos dos relatos dos trabalhadores de forma negativa (ou não praticada). Um exemplo disto, é a luta dos técnicoadministrativos no que tange a liberdade de criarem projetos de pesquisa e extensão dentro da organização. O histórico tem demonstrado que vários técnicos atuam como colaboradores quando incluídos nos projetos que são maciçamente "dos docentes". Durham (2006) afirma que a estrutura da administração pública brasileira está formulada para garantir um forte controle burocrático nas instituições que integram, sem nenhum (ou pouco) espaço para a autonomia. Em especial a partir da década de noventa do século passado, têm sido realizadas tentativas de reformas no serviço público brasileiro com vistas a eliminar essas disfunções, expressas por meio de rigidez, hierarquização, endogenia, custos elevados, ineficiência e prestação de serviços mal avaliados pelos usuários (Ribeiro \& Mancebo, 2013). De tal forma que a administração pública brasileira e universitária tenta ao longo dos anos romper essas "amarras burocráticas" como forma de tornar as instituições mais ágeis e flexíveis (Durham, 2006).

Possivelmente uma das explicações para o valor autônoma ter um alto índice de não praticado, é a compreensão sobre a autonomia universitária, vinculada a luta dos técnicoadministrativos que vem acontecendo nos últimos anos, as 30 horas semanais. Esta pauta tem provocado diversas discussões ao longo dos tempos, em que um lado diz ser legal a implantação das 30h, e outro diz o revés, que não tem autonomia para decidir tal situação - conforme visualizado no discurso: "Percebe-se uma estagnação na universidade sobre novas possibilidades de administração como por exemplo as $30 \mathrm{hrs}$ que desde sempre foram rejeitadas pela reitoria [...]" (P186). Segundo grupo de trabalho Reorganiza UFSC (Reorganiza UFSC, 2013) as bases legais, apresentadas pelos órgãos de controle e MEC, que impossibilitam essa iniciativa, ressaltam apenas a ingerência desses órgãos e sua desconsideração pela autonomia universitária.

Os dois valores (bem administrada e planejada; saudável) não praticados com maior incidência são constantemente ressaltados, de forma negativa, pelos participantes da pesquisa. A crítica existente dos participantes da pesquisa não é exclusiva sobre a atual gestão, embora exista, mas repercute também nas gestões anteriores. Como pode ser observado nas verbalizações em sequência: "Minha opinião sobre o funcionamento interno está tão negativa que a melhor propaganda que faço é com o silêncio" (P54).

Infelizmente a instituição vem sendo mal administrada ao longo dos anos, os setores estão sucateados e com falta principalmente de funcionários técnico-administrativos em quase todos os setores, sobrecarregando o restante. Fica muito difícil prestar um serviço de qualidade sem o material necessário (ou até mesmo a manutenção dos já existentes) e com falta de pessoas (P20).

Segundo Grass e Grambach (1968, apud Baldridge, 1982), a universidade é uma "anarquia organizada", isso devido a ela possuir diferentes modelos de administração nem sempre confluentes, como os modelos burocrático, colegiado e o político. Não obstante, é possível fazer uma relação das verbalizações com um ditado popular, "Casa de ferreiro, espeto de pau".

Com um ambiente de trabalho "insalubre", seja pela má administração, pelo corporativismo existente, pela falta de ética, e outras mazelas existentes, necessariamente estas ocorrências afetam a saúde e a qualidade de vida dos trabalhadores. Nesse sentido, ocorrem os afastamentos laborais, o descontentamento com o trabalho, os adoecimentos e outras situações que afetam todo o funcionamento da organização. A degradação das condições de trabalho, muitas vezes se traduzem no aumento das doenças profissionais, da precarização dos estatutos, do sofrimento no trabalho, e da insegurança social (Gaulejac, 2007; Nunes \& Tolfo, 2013).

Para desvendar sobre o porquê dos valores esposados não serem praticados na UFSC, foi questionado aos participantes quais seriam os motivos. Neste caso, os motivos foram diversos e também repetitivos, tais como: burocracia, falta de planejamento, interesses pessoais e grupos sobrepostos aos interesses organizacionais, má gestão, falta de responsabilidade e comprometimento dos gestores e dos próprios trabalhadores, discursos versus a prática, e demais. 
Quadro 2: Valores organizacionais: percepções do porquê de não prática

\begin{tabular}{|c|c|}
\hline $\begin{array}{l}\text { VALORES } \\
\text { DECLARADOS }\end{array}$ & PERCEPÇÕES DO PORQUÊ DE NÃO PRÁTICA \\
\hline $\begin{array}{l}\text { Acadêmica e de } \\
\text { Qualidade }\end{array}$ & $\begin{array}{l}\text { - "Suposta qualidade medida pela quantidade de publicações com vistas a aumentar o 'conceito' do professor orientador } \\
\text { e aumentar sua remuneração, enquanto visa inflacionar o conceito acadêmico da universidade, em oposição à } \\
\text { persecução da efetiva qualidade dos trabalhos científicos, medindo-se, por exemplo, quantos destes são referências } \\
\text { de âmbito internacional em sua área de conhecimento" (P129). }\end{array}$ \\
\hline Atuante & $\begin{array}{l}\text { - "Ousada, Culta e Atuante: a UFSC opta por contratar empresas, pagando valores altíssimos, quanto em alguns casos } \\
\text { poderia utilizar a tecnologia que possui em seus centros de ensino" (P56). }\end{array}$ \\
\hline Autônoma & $\begin{array}{l}\text { - "A administração atual da UFSC está ligada diretamente ao que o MEC determina. Não há autonomia universitária, } \\
\text { especialmente no que diz respeito à gestão" (P24). } \\
\text { - "A autonomia universitária é relativa, devido às influências e pressões do Governo Federal" (P54). }\end{array}$ \\
\hline $\begin{array}{l}\text { Bem Administrada e } \\
\text { Planejada }\end{array}$ & $\begin{array}{l}\text { - "Se há algo que não existe na UFSC é isso, planejamento. Sinto que estamos sempre apagando incêndios, ao invés } \\
\text { de buscando cumprir objetivos" (P24). } \\
\text { - "À UFSC falta planejamento de longo prazo; os problemas viram prioridade apenas quando estouram. Cada } \\
\text { administração pensa em resolver a situação hoje; o amanhã que fique para depois" (P54). } \\
\text { - "Falta de visão global e efetivação das não conformidades mapeadas. Regência política em detrimento da regência } \\
\text { institucional-técnica" (P55). }\end{array}$ \\
\hline Culta & $\begin{array}{l}\text { - "Apesar de produzir muito conhecimento no campo da ciência, pouco disso chega à comunidade. No campo das artes, } \\
\text { muito pouco é produzido" (P24). } \\
\text { - "Com exceção da produção técnica e científica do Centro Tecnológico da UFSC, reconhecido internacionalmente pela } \\
\text { academia e pelo mercado, a universidade não é culta, como consequência lógica e direta da baixa qualidade } \\
\text { acadêmica: ainda que a UFSC seja excelente em comparação com a grande maioria das demais universidades } \\
\text { brasileiras, que se encontram em situação bastante mais grave" (P129). }\end{array}$ \\
\hline Democrática e Plural & $\begin{array}{l}\text { - "A UFSC não pode ser democrática, bem-administrada, saudável e responsável enquanto tratar os servidores técnico- } \\
\text { administrativos como servidores de menor valor" (P53). } \\
\text { - "A democracia na UFSC é frágil, propõe-se teatros de discussões, mas a decisão final da reitoria continuará a mesma" } \\
\text { (P54). } \\
\text { - "Lamentavelmente contaminada por ideologias e por paternalismo" (P55). }\end{array}$ \\
\hline Livre & $\begin{array}{l}\text { - "Acredito que ninguém se sinta realmente livre na UFSC. Há muita burocracia e luta de poderes internos que } \\
\text { prejudicam o dia-a-dia de todas as classes" (P24). } \\
\text { - "Os servidores não são livres para manifestar-se e desenvolver suas convicções, pois tudo se dá 'a interesse da } \\
\text { administração'” (P111). } \\
\text { - "Porque não me sinto livre nem mesmo para expressar as minhas opiniões em certos momentos. Professores novos } \\
\text { e também vários outros já mais antigos participam das reuniões e permanecem calados, com medo de falar, nem } \\
\text { sempre são ouvidos e, muitas vezes, só a opinião de quem detém o poder é considerada" (P165). }\end{array}$ \\
\hline Ousada & $\begin{array}{l}\text { - "Não é atuante e ousada porque muitas vezes os debates de temas relevantes não produzem soluções, pois falta } \\
\text { conhecimento prático para muitos dos atores" (P53). }\end{array}$ \\
\hline Saudável & $\begin{array}{l}\text { - "Se a saúde fosse valorizada na UFSC, os servidores teriam equipamentos de proteção e segurança, haveria } \\
\text { ergonomia, haveria incentivos à prática de exercícios e à alimentação saudável. Minha qualidade de vida diminuiu ao } \\
\text { começar a trabalhar aqui (salário baixo, muitas responsabilidades, desmotivação no setor, falta de comunicação, etc)" } \\
\text { (P54). } \\
\text { - "A UFSC não é uma instituição saudável para os docentes porque há sobrecarga de trabalho e, principalmente, } \\
\text { precariedade nas relações interpessoais entre os docentes, incluindo aí o assédio moral" (P165). } \\
\text { - "É claro que não há preocupação nenhuma com a saúde e qualidade de vida do trabalhador pois não há nenhuma } \\
\text { fiscalização de chefias, o processo de avaliação do estágio probatório vitimiza os funcionários novos e o assédio moral } \\
\text { é constante e intenso, porém difícil de ser provado" (P186). }\end{array}$ \\
\hline Responsável & $\begin{array}{l}\text { - "Muito pouco se faz na área de proteção ambiental e há sérios problemas éticos envolvendo a administração e as } \\
\text { relações entre docentes e TAEs" (P24). } \\
\text { - "A instituição é composta por pessoas que não aplicam os valores de democracia, de sustentabilidade, consciência } \\
\text { ambiental. A UFSC é uma hipocrisia, oferece disciplinas de Sustentabilidade e cursos nesta temática, entretanto não } \\
\text { aplica a Coleta Seletiva. Nossa comunidade acadêmica é maior em população do que algumas cidades do interior do } \\
\text { estado. É decepcionante" (P37). }\end{array}$ \\
\hline
\end{tabular}

Conforme pode ser visualizado no Quadro 2, há uma série de verbalizações dos participantes sobre os motivos pelos quais determinados valores não são praticados dentro da Universidade e as situações foram elencadas no respectivo valor declarado. $A$ explicitação destes não pressupõe que eles não são praticados, mas evidencia algumas situações ou motivos que impedem a plena valorização dos mesmos, fato que, segundo Garcia (2016), pode implicar em consequências negativas para a confiança na organização.

Por sua vez, existem ainda "subgrupos de poder que subjugam os valores institucionais em busca de seus interesses específicos" (P195), conforme já mencionado em outros momentos. Segundo Gaulejac (2007) a política está longe de provocar o amor e a consideração, pois tornou-se um lugar do cálculo, percebida como uma forma de direcionar o serviço para interesses próprios. Ou seja, a "coisa pública" é desvalorizada. Dessa forma, os interesses individuais ou de determinado grupo se tornam mais importantes do que os próprios objetivos organizacionais. Não obstante,
[...] valores que deveriam estar amalgamados no comportamento social e profissional de toda a comunidade UFSC, mas compreendo que há muitas dificuldades e barreiras para que sejam praticados, pois dependem em parte da cultura - individual e coletivamente, de fatores econômicos e vontade política (P204).

Segundo Motta e Alcadipani (1999, p. 8) no Brasil, "[...] os interesses pessoais são tidos como mais importantes do que os do conjunto da sociedade, ocasionando falta de coesão na vida social brasileira, na medida em que cada um favorece os seus e os membros de seu 'clã' em detrimento do interesse coletivo". O compartilhamento de interesses de grupos são descritos como sobrepostos ao compartilhamento de valores organizacionais (Tolfo, Silva, \& Krawulski, 2013). Além dos aspectos levantados, cabe responsabilidade também às gestões, sejam da administração central ou dos setores, uma vez que "muitos desses valores não são praticados devido à forma de gestão adotada na UFSC. Não apenas na administração central" (P51).

Situações mais além foram reforçadas pelos participantes ao comentarem que a UFSC, independentemente de suas especificidades, é uma instituição pública, que apresenta os mesmos vícios e problemas que a maioria das outras instituições 
brasileiras. Conforme podemos observar notícias nas mídias, segundo um dos participantes da pesquisa, "o Brasil inteiro sofre de falta de ética, comprometimento e valores morais. A UFSC é uma boa representante disso" (P166).

De um modo geral, os vícios da UFSC são comuns a quase todas as instituições públicas brasileiras: excesso de burocracia, desleixo administrativo, pouca ou nenhuma preocupação com a coisa pública. Mas está longe de ser uma das piores instituições que conheci, e há muitas pessoas lutando para estabelecer bons valores em suas áreas de atuação (P176).

Os problemas e situações elencados existem em grande parte dos lugares e setores, e em um ambiente de muita diversidade e complexidade, como é a instituição universitária, não há como fugir à regra. Por sua vez, em muitos momentos existem discursos, em geral proferidos por aqueles que estão no poder, que enfatizam aspectos de mudanças positivas, da prática dos valores organizacionais, da ética, e dos bons comportamentos. No entanto, muitos desses são palavras vazias que ficam apenas nas falas, e suas práticas continuam as mesmas. Portanto, é fundamental que a organização (gestão e trabalhadores) não fique apenas nos discursos, para que não exista uma discrepância entre o oficial (discursado) e o praticado (Sina, 2007; Nunes, Tolfo, \& Nunes, 2013). Assim, cabe principalmente à gestão, o desenvolvimento de práticas e políticas para que esta inconsistência entre discurso e prática não ocorra.

Desta forma, foi questionado aos participantes se há diferença entre o discurso e a prática dos valores na UFSC, e como isso ocorre.

Então sobre o discurso particularmente, eu vejo que quem está no poder tem um discurso muito igual, vai e volta. Assume o cargo e acaba assumindo um discurso pronto, e que esse discurso não reflete sua pratica. Isso eu já tenho notado como cultura organizacional (P32).

No nosso departamento é muito claro, é muito explícita a diferenciação [...] Quem não é da maçonaria, não é beneficiado. Eu chamo de reserva de mercado: eu te protejo e você me protege, e assim nós vamos lidando e eu não facilito e não oportunizo ninguém que seja externo a esse grupo, por mais que essa pessoa tenha produção (P37).

A arte do discurso pode ser muito praticada em qualquer ambiente, seja no laboral ou nas demais relações cotidianas. As práticas muitas vezes não estão em consonância com os discursos, o que caracteriza um paradoxo organizacional, uma incoerência entre o que é explicitado e o que é feito. Por sua vez, é concedida mais ênfase aos discursos dos gestores, pois são eles que orientam e coordenam as atividades na organização e estabelecem procedimentos e normas, por meio de políticas e de modelos. Modelos de gestão estão presentes em praticamente todas as diversas organizações, embora todos os seus componentes não sejam claramente perceptíveis. Geralmente são mais ou menos consolidados em uma estrutura singular da organização, ou podem ser menos tangíveis (Fischer, 2002). De modo especial, segundo o mesmo autor, "os componentes formais de um modelo de gestão de pessoas se definem por princípios, políticas e processos que interferem nas relações humanas no interior das organizações" ( $p$. 17). Os princípios são fundamentais para orientar os valores e as crenças básicas subjacentes ao modelo, e que se espera que sejam adotadas pelos componentes da empresa (Tolfo, Silva, \& Krawulski, 2013).

Chanlat (1997), por sua vez, aponta a existência de dois componentes em todos os modos de gestão: um abstrato, prescrito, formal e estático, denominado modo de gestão prescrito, e outro concreto, real, informal e dinâmico, chamado de modo de gestão real. Muitas vezes, há contradições entre os modos de gestão prescrito e real, segundo o autor, o que não fornece base sólida para a formação de um sentimento de confiança recíproco, tampouco oferece terreno propício para o desenvolvimento de identidades coletivas. Esses paradoxos trazem inseguranças sobre as formas corretas de agir no ambiente organizacional. Para Hogan e Coote (2014) as normas refletem as expectativas sociais que aparecem dos valores organizacionais subjacentes, e dessa forma, representam as regras/normas comportamentais que orientam as ações do coletivo social. Existe uma dificuldade dos gestores desenvolverem uma identidade coerente com seu discurso, o que provoca críticas dos trabalhadores e um sentimento de injustiça (Pires \& Macêdo, 2006). Mas não são apenas aqueles que estão no poder que apresentam essa dissonância entre discurso e prática, pois, em geral os próprios trabalhadores desenvolvem discursos, e suas práticas não mudam, seja por comodismo ou por desinteresse.

De acordo com Lacombe e Tonelli (2004), a existência simultânea de duas realidades contraditórias (o discurso da organização e sua prática em relação a um mesmo objeto) gera percepções inconsistentes nos indivíduos, que polarizam a interpretação da realidade ao seu redor entre as dimensões opostas "discurso" e "prática". Ao assimilar promessas e discursos gerenciais que produzem expectativas, mas que não se realizam, alguns funcionários podem desenvolver reações defensivas que aumentam o nível de frustração, tensão e estresse no sistema organizacional. Segundo Zanini (2007) e Garcia (2016) a percepção comum de justiça dentro da empresa influencia significativamente os investimentos de confiança entre os membros de uma organização. A percepção dos valores organizacionais pelos trabalhadores cria uma imagem da organização quanto a suas práticas, gestão e demais. E, a partir dessas características da imagem, é determinada a identificação dele com a organização e seus objetivos (Vieira \& Gomes, 2013). Ou seja, os valores não só influenciam o comportamento do trabalhador com seu meio, mas também seu julgamento/análise que ele faz do outro em relação ao sistema organizacional (Vieira \& Gomes, 2013).

A prática, pouca prática ou não prática dos valores esposados pela Universidade, além dos aspectos levantados nesta subseção, também leva em conta como os trabalhadores se identificam com estes valores. Desta forma, a subseção seguinte apresenta exatamente este importante aspecto na discussão sobre os valores organizacionais.

\subsection{Identificação com os valores organizacionais}

Esta subcategoria apresenta os relatos dos participantes sobre a sua identificação com os valores declarados da UFSC. Assim, foi questionado se eles se identificam com os valores da Universidade. 
As verbalizações dos participantes basicamente estão vinculados a dois elementos: interesses próprios, que não representam um aspecto negativo em si, mas que pode colaborar com o desenvolvimento da organização e profissional e pessoal do trabalhador; obstáculos, os quais impedem a identificação dos valores organizacionais.

Muitos trabalhadores se identificaram com alguns dos valores declarados pela Universidade, conforme pode ser visualizado a seguir: "Sim, na medida em que busco responder a sociedade, através da formação de cidadãos mais críticos, autônomos, agindo com ética no campo profissional" (P161); "Sim, pois muitos destes valores carrego comigo, no meu dia a dia, tentando fazer o meu trabalho da melhor maneira possível, sempre pensando em ajudar a instituição a cumprir sua missão" (P185); "Sim. Porque busco continuamente a minha qualificação, a fim de contribuir com a melhoria da UFSC em termos de excelência acadêmica, inovação, estratégias de gestão, etc." (P212).

Em muitas verbalizações há a identificação e relação dos valores declarados da organização com os próprios valores e práticas dos trabalhadores dentro da mesma. E, desta forma, contribuem para a perpetuação dos valores e o desenvolvimento da organização. Isso também repercute no próprio aperfeiçoamento individual do trabalhador, seja no campo de profissional ou pessoal. De acordo com Freitas (2007), os valores são importantes pois podem elevar o comprometimento com a organização, o sentimento de sucesso pessoal e a autoconfiança. Ademais, os valores organizacionais além de fortalecer a cultura e a identidade organizacional, fortalece os princípios motivacionais do trabalhador (Vieira \& Gomes, 2013).

A não identificação com os valores declarados pela Universidade é algo raro de acontecer, uma vez que estes englobam muitas atividades e comportamentos que os trabalhadores exercem tanto no trabalho quando na sua vida pessoal. No entanto, existem percepções que enfatizam a não identificação com estes valores: "Gostaria, mas não. Não nos é dado tempo hábil para inovar, estudar em novas propostas, ser saudável, proporcionar um serviço de qualidade. Passamos a maior parte do tempo resolvendo problemas da falta de planejamento" (P125); "Não! Não me identificarei com os valores da UFSC enquanto estes se mostrarem falsos [...]" (P75).

Existem, portanto, barreiras e situações que muitas vezes obstaculizam a prática dos valores propostos pela Universidade. Conforme pode ser visualizado nas seguintes verbalizações: "Não adianta ter valores se eles são corrompidos diariamente nos relacionamentos e nas atividades de ensino, pesquisa e extensão. Nossa universidade não tem nada de democrática" (P10); "Há setores, profissionais que não se associam a estes valores, ou seja, buscam na UFSC o predomínio de benefícios pessoais em detrimento das necessidades institucionais" (P89). Além disto:

Os valores expressos formalmente são admiráveis, porém, a prática é diferente. Alguns funcionários têm suas potencialidades cerceadas por chefias que não sabem administrar o corpo técnico.

[...] A busca por qualidade acadêmica está deixando a desejar pelo alto número de discentes ao mesmo tempo que a estrutura para atender a demanda está deficitária. Não há liberdade de expressão. Há casos de ameaças de retaliações de chefias quando o funcionário discorda de sua opinião. Muitas pesquisas são realizadas de forma descolada da sociedade e sem nenhuma relevância (P178).

Grande parte dos fatores obstaculizadores tem como elementos: problemas nos relacionamentos interpessoais; proteção de alguns trabalhadores; punição para outros; práticas e ações movidas por interesses pessoais ou grupais; ambiente de trabalho precário/conflituoso; retaliações por discordar da opinião ou posição de outrem; falta de interesse da gestão em determinadas situações. Essas características estão muito presentes na administração pública brasileira, tal como preconiza Carbone (2000), seja pelo paternalismo, o levar vantagem, o autoritarismo e o desinteresse dos gestores. Há evidentemente muitas situações que prejudicam o bom e correto funcionamento organizacional, além dos destacados anteriormente, não se pode esquecer do aspecto político: "Certamente me identifico com os valores da UFSC e lamento ver que muitas vezes estes são ignorados por questões políticas locais" (P45). A considerável autonomia operacional das organizações públicas brasileira, muitas vezes tende a provocar privilégios clientelistas, favoritismos, corporativismo e outros "ismos”, quando não a corrupção (Castor \& José, 1998), que vão de encontro aos propósitos declarados do profissionalismo no serviço público, conforme afirmam Tolfo, Silva e Krawulski (2015). Estes autores citam Chanlat (1997), que identifica dois componentes nos modos de gestão: um formal e estático - o modo de gestão prescrito, e outro concreto, informal e dinâmico - o modo de gestão real. Podem haver dissonâncias entre os dois modos de gestão (prescrito e real) e isso não edifica bases sustentáveis para gerar sentimentos de confiança e reciprocidade, nem condições para desenvolver identidades coletivas. Contradições deste tipo ocasionam respostas como as encontradas na pesquisa e que geram irritação e inseguranças quanto as melhores formas de agir na organização.

Para Hogan e Coote (2014) as normas refletem as expectativas sociais que aparecem dos valores organizacionais subjacentes, e, dessa forma, representam as regras/normas comportamentais que orientam as ações do coletivo social. Em um dos poucos textos clássicos que abordam especificamente a cultura em organizações públicas, Pires e Macêdo (2006) afirmam que existe uma dificuldade dos gestores das mesmas em desenvolverem uma identidade coerente com seu discurso, o que provoca críticas dos servidores e um sentimento de injustiça. Mas não são apenas aqueles que estão no poder que apresentam essa dissonância entre discurso e prática, pois, em geral, os próprios subordinados desenvolvem discursos, e suas práticas não mudam, seja por comodismo ou por desinteresse. Dessa forma, as incertezas provocadas nas relações podem abalar a predisposição dos trabalhadores na sua confiança com o outro e na organização, tornando as relações mais imprevisíveis e diminuindo os níveis de confiabilidade (Zanini \& Migueles, 2014).

Não obstante, pesquisadores e especialistas afirmam que a conformidade entre os valores pessoais e organizacionais é um importante fator que auxilia a manter a força de trabalho adaptável 
e comprometida com a organização, o que é algo fundamental no mundo laboral atual (Veinhardt \& Gulbovaitè, 2015). Esta conformidade pode influenciar com a satisfação no trabalho, comprometimento com a organização, intenção de deixar o trabalho, motivação, iniciativa dos trabalhadores, desempenho no trabalho, burnout, percepção da marca, estresse e ansiedade, comportamentos éticos e demais (Veinhardt \& Gulbovaitè, 2015). Ou seja, a identificação ou não com os valores influencia o trabalhador de alguma forma.

$\mathrm{Na}$ subseção anterior, sobre a prática dos valores organizacionais foi questionado sobre a diferença entre o discurso e a prática dos valores na UFSC - o que foi evidenciado que existe. Ao continuar sobre os obstáculos da identificação com os valores organizacionais ou até mesmo da prática destes valores, muitos dos participantes da pesquisa relacionam um problema comum dentro da qualquer organização, pública ou privada, e até na vida em sociedade - a diferença entre o escrito/falado e prática, ou entre a teoria e a prática. Tais aspectos podem ser constatados nas seguintes verbalizações: "[Me identifico] Com a grande maioria, pena que muitos existem somente no papel" (P67); "Me identifico com muitos dos valores escritos, mas não tenho me identificado com a prática institucional" (P88); "Os valores são anteriores a todos os membros da comunidade universitária e para muitos é tão abstrata quanto os 10 Mandamentos. Há mais um desejo de que fosse verdade do que uma identificação" (P108).

Para Vieira e Gomes (2013) no contexto do comportamento organizacional, os valores pessoais, organizacionais e comprometimento devem estar interligados, o que possibilita ao servidor a consciência do seu valor social e profissional. Além disto, possibilita ao mesmo, "[...] internalizar a ideia de que é um dever ético proteger o seu conceito profissional e sua conduta perante a sociedade a quem presta serviços" (Vieira \& Gomes, 2013, p. 82).

Os valores declarados são bem formulados em teoria e englobam diversas áreas importantes para o bom funcionamento, convívio e atuação externa da organização. Porém, conforme os relatos anteriores (e muitos outros já mencionados em diversos momentos), a prática é bem diferente do exposto, naquilo que é falado ou escrito pela gestão(ões) da organização e trabalhadores. Logo, existe um problema já perpetuado ao longo do tempo na Universidade, pois isto não é uma situação da atual gestão, mas percorre um longo caminho na sua história e também é presente no Estado e em diversas instituições brasileiras. As organizações públicas brasileiras geralmente têm a organização do trabalho pautada na especialização e no tecnicismo, e tanto o volume de trabalho quanto os processos burocráticos contribuem para a adoção de soluções pragmáticas, propícias a manutenção das estruturas vigentes (Suxberger, 2009).

\section{CONSIDERAÇÕES FINAIS}

O principal objetivo deste estudo foi descrever a percepção dos servidores docentes e técnico-administrativos em relação aos valores organizacionais declarados e praticados na Universidade Federal de Santa Catarina, bem como a identificação com os valores da organização. Para tanto, procurou-se compreender os valores organizacionais como componentes centrais da cultura, e que servem de orientação para os aspectos inconscientes e os comportamentos organizacionais (Schein, 2001; 2009; Tamayo, 2004; 2007; Tamayo \& Borges, 2006).

Os resultados do estudo demostraram, por meio da subcategoria práticas dos valores organizacionais, que os valores mais praticados na Universidade, segundo os participantes, estão relacionados ao ensino - internacionalizada $(78,5 \%)$; acadêmica e de qualidade (77,6\%); culta (61,2\%); e atuante (56,5\%). Em contrapartida, os menos praticados foram democrática e plural $(50 \%)$, responsável $(51,4 \%)$, livre $(56,1 \%)$, ousada $(59,8 \%)$, autônoma $(60,7 \%)$, saudável $(74,3 \%)$, bem administrada e planejada (81,8\%). Muitos dos valores não praticados, em especial bem administrada e planejada, e saudável, foram alvo de críticas em outras partes deste trabalho, como por exemplo, quando é ressaltada a ineficiência da gestão no planejamento e administração, a deterioração das condições de trabalho e da qualidade de vida do trabalhador. Ressalta-se que o espaço da sociedade na qual a liberdade de expressão, especialmente plural, deveria ser exercita, não tem cumprido o seu papel de contribuir para a democracia, especialmente em um país como o nosso com histórico recente de exercício democrático.

A respeito dos principais motivos relacionados à incongruência entre valores declarados e praticados, as situações elencadas pelos participantes estão relacionadas ao excesso de burocracia; falta de interesse da gestão; sobreposição de interesses individuais ou de grupos dominantes em detrimento aos interesses institucionais: política; má administração; corporativismo; falta de ética; desigualdade entre servidores docentes e técnico-administrativos; falta de infraestrutura; disparidades entre o discurso e práticas; e outros. Tais elementos, repetitivos, estão presentes constantemente dentro da Universidade, e isso faz com que os próprios trabalhadores tenham problemas para se identificar com os valores organizacionais, os declarados. A presença da ambiguidade é um forte estressor para os trabalhadores, pois confere incertezas em relação ao real funcionamento da instituição, das relações, e do trabalho; e especialmente se suas expectativas não ocorrem.

Assim, na subcategoria identificação com os valores organizacionais, o foco era se o trabalhador se identifica com os valores declarados, e também os obstáculos que inibem que isso ocorra. Nos discursos foi possível verificar que os trabalhadores se identificam com alguns dos valores declarados da organização, os quais norteiam os comportamentos e ações dos trabalhadores, em prol do desenvolvimento pessoal e institucional. No entanto, o mais enfatizado foram as barreiras que impedem as práticas (identificação) destes valores, sendo que tais barreiras são as mesmas destacadas no parágrafo anterior. Estas "barreiras" estão presentes na própria história organizacional, e tem influência nas políticas de gestão institucional, e nas normativas e valores organizacionais. São aspectos verificados nas verbalizações dos entrevistados, e são enfatizados como causadores dos problemas da organização. Porém, os mesmos são criticados, praticados e perpetuados pelos próprios trabalhadores, uma vez que a cultura contribui para fortalecer comportamentos aprendidos. 
Com base nas considerações apresentadas, recomenda-se a realização de futuros estudos, no mesmo contexto pesquisado, que possibilitem investigar com mais propriedade as possíveis congruências e incongruências entre os valores declarados e praticados, bem como a identificação dos servidores com os valores, podendo ser relacionado a outros fenômenos como comprometimento e motivação no trabalho. Outra sugestão seria a realização de pesquisas que procurem identificar as interconexões entre os valores e confiança organizacionais, segundo a percepção dos servidores e de membros da sociedade, na qual a universidade está inserida, ampliando a compreensão do estudo para os demais atores organizacionais.

Por fim, dentre as limitações possível para esta pesquisa, destaca-se a qualidade das informações obtidas pelos participantes em estudo que privilegiou a coleta de dados por meio da observação indireta (questionários). Pesquisas sobre cultura apresentam dificuldades quando pessoas estão envolvidas, uma vez que elas tendem a resistir, ocultar dados, e manter-se na defesa ou exageram um pouco para impressionar o pesquisador (Schein, 2009). Além disto, o levantamento de dados restringiu-se à aplicação de questionário online, o que não permitiu captar e discutir com maior profundidade as percepções dos servidores universitários (docentes e técnico-administrativos) sobre os valores organizacionais.

\section{AGRADECIMENTOS}

Agradecimentos especiais à Coordenação de Aperfeiçoamento de Pessoal de Nível Superior (CAPES) pelo apoio e financiamento destinado ao projeto a qual este trabalho científico se originou. Bolsista da CAPES - Processo BEX 9426/14-0.

\section{REFERÊNCIAS}

Baldridge, V. J. (1982). Estruturacion de políticas e liderazgo efectivo en la educacion superior. México: Noema.

Bardin, L. (2004). Análise de conteúdo. 3. ed. Lisboa: Edições 70.

Carbone, P. (2000). Cultura organizacional do setor público brasileiro: desenvolvimento de uma metodologia de gerenciamento da cultura. Revista de Administração Pública, 34(2), 1-5.

Castor, B. V. J., \& José, H. A. A. (1998). Reforma e contra-reforma: a perversa dinâmica da administração pública brasileira. Revista de Administração Pública, 32(6), 97-111.

Chanlat, J. F. (1997). Modos de gestão, saúde e segurança no trabalho. In E. P. B. Davel, \& J. G. M. Vasconcellos (Orgs.). "Recursos Humanos" e subjetividade (pp. 118-128). Petrópolis: Vozes.

Creswell, J. W. (2007). Projeto de pesquisa: métodos qualitativo, quantitativo e misto. 2 ed. Porto Alegre: Artmed.

Deal, T. E., \& Kennedy, A. (2000). Corporate Cultures: the rites and rituals of corporate life. USA: Basic Books.

Demo, G.; Fernandes, T., \& Fogaça, N. (2017). A influência dos valores organizacionais na percepção de políticas e práticas de gestão de pessoas. Revista eletrônica de Administração, 23(1), 89-117.

Dominico, S. M. R., \& Latorre, S. Z. (2008). A relação entre tipos de cultura organizacional e valores organizacionais. In- M. L. M. Teixeira (Org.). Valores humanos \& gestão: novas perspectivas (pp. 245-269). São Paulo: Editora Senac.

Durham, E. R. (2006). A autonomia universitária: extensão e limites. In J. E. Steiner, \& G. Malnic (Org.). Ensino Superior: conceito e dinâmica (pp. 79124). São Paulo: EDUSP.

Ferreira, M. C., \& Assmar, E. M. L. (1999). Perspectivas epistemológicas, teóricas e metodológicas no estudo de cultura organizacional. Revista Educação e Tecnologia, 4, 1-11.

Finger, A. P. (1988). Gestão acadêmica. In A. P. Finger (Org.). Gestão Acadêmica em Universidade: Organização, Planejamento, Gestão. Florianópolis (SC), UFSC/CPGA/NUPEAU.9

Fischer, A. L. (2002). Um resgate conceitual e histórico dos modelos de gestão de pessoas. In M. T. L. Fleury (Org.). As pessoas na organização (pp. 11-34). São Paulo: Editora Gente.
Fleury, M. T. L. (1987). Estória, mitos, heróis: cultura organizacional e relações de trabalho. Revista de Administração de Empresa - RAE, 27(4), 7 18.

Fleury, M. T. L. (1996). O desvendar a cultura de uma organização - uma discussão metodológica. In: M. T. L. Fleury, \& R. M. Fischer (Coords). Cultura e poder nas organizações (pp. 15-27). 2.ed. São Paulo: Atlas.

Freitas, M. E. (1991). Cultura organizacional: grandes termas em debate. Revista de Administração de Empresa - RAE, 31(3), 73-82.

Freitas, M. E. (2007). Cultura Organizacional: evolução e crítica. São Paulo: Thomson Learning.

Garcia, I. S. (2016). Interconexões entre valores e confiança organizacionais: o caso de uma empresa familiar da grande Florianópolis. 2016. 352p. Tese (Doutorado) - Universidade Federal de Santa Catarina, Centro de Filosofia e Ciências Humanas, Programa de Pós-Graduação em Psicologia, Florianópolis.

Gaulejac, V. (2007). Gestão como doença social: ideologia, poder gerencialista e fragmentação social. Aparecida, SP: Idéias \& Letras.

Geertz, C. (1989). A Interpretação das Culturas. Rio de Janeiro: LTC.

Gil, A. C. (2007). Métodos e técnicas de pesquisa social. 5 ed. São Paulo: Atlas.

Gouvêa, R. Q. (2008). Da filosofia dos valores a uma ciência dos valores. In M. L. M. Teixeira (Org.). Valores humanos e gestão: novas perspectivas (pp. 17-45). São Paulo: Editora Senac.

Hofstede, G. (1980). Culture's consequences: international differences in work related values. Beverly Hills: Sage.

Hogan, S. J., \& Coote, L. V. (2014). Organizational culture, innovation, and performance: a test of Schein's model. Journal of Business Research, 67(8), 1609-1621.

Katz. D., \& Kahn, R. L. (1974). Psicologia social das organizações. São Paulo: Atlas.

Lacombe, B. M. B., \& Tonelli, M. J. (2004). O paradoxo básico da administração de recursos humanos: o discurso versus a prática de gestão de pessoas nas empresas. In F. C. Vasconcelos, \& I. F.G. Vasconcelos. Paradoxos organizacionais: uma visão transformacional (pp. 53-74). São Paulo: Pioneira.

Ludke, M., \& André, M. E. D. A. (1986). Pesquisa em educação: abordagens qualitativas. São Paulo: EPU.

Marconi, M. A., \& Lakatos, E. M. (2009). Metodologia do Trabalho Científico.7. ed. São Paulo: Atlas.

Minayo, M. C. S. (Org.). (1994). Pesquisa social: teoria, método e criatividade. Rio de Janeiro: Vozes.

Motta, F. C. P., \& Alcadipani, R. (1999). Jeitinho brasileiro, controle social e competição. Revista de Administração de Empresas - RAE, 39(1), 6-12.

Nascimento, T. G., Castro, B. G. A., Carvalho, G. P., \& Demo, G. (2016). Valores organizacionais: uma análise bibliométrica da produção nacional do período de 2000 a 2013 na área de administração. Organizações em contexto, 12(24), 37-64.

Nunes, T. S., \& Tolfo, S. R. (2013). A dinâmica e os fatores organizacionais propiciadores à ocorrência do assédio moral no trabalho. Revista de Gestão e Secretariado - GeSec, 4(2), 90-113.

Nunes, T. S., Tolfo, S. R., \& Nunes, L. S. (2013). Assédio Moral em Universidade: a violência identificada por servidores docentes e técnicoadministrativos. Organizações em contexto, 9(18), 25-61.

Pires, J. C. S., \& Macêdo, K. B. (2006). Cultura organizacional em organizações públicas no Brasil. Revista de Administração Pública, 40(1), 81 105.

Porto, J. B., \& Pilati, R. (2010). Escala revisada de valores relativos ao trabalho - EVT-R. Psicologia: reflexão e crítica, 23(1), 73-82.

Reorganiza UFSC. (2013). Grupo de Trabalho Reorganiza UFSC. Secretaria de Gestão de Pessoas - SEGESP. UFSC. Relatório. Florianópolis.

Ribeiro, C. V. S., \& Mancebo, D. (2013). O servidor público no mundo do trabalho do século XXI. Psicologia: Ciência e Profissão, 33(1), 192-207.

Richardson, R. J. (2008). Pesquisa Social: métodos e técnicas. 3. ed. São Paulo: Atlas.

Santos, J. L. (2004). O que é cultura. São Paulo: Brasiliense.

Schein, E. H. (2001). Guia de sobrevivência da cultura corporativa. Rio de Janeiro: José Olímpio.

Schein, E. H. (2009). Cultura organizacional e liderança. São Paulo: Atlas.

Silva, A. L. G., \& Silva, N. (2010). Percepções de valores organizacionais declarados de uma organização educacional. Interação em Psicologia, 14(1), 83-92.

Silva, N., \& Zanelli, J. C. (2004). Cultura organizacional. In J. C. Zanelli, J. E. Borges-Andrade, \& A. V. B. Bastos. Psicologia, organizações e trabalho no Brasil (pp. 407-442). Porto Alegre: Artmed.

Silva, N., Zanelli, J. C., \& Tolfo, S. R. (2013). Diagnóstico e gestão da cultura nas organizações. In L. O. Borges, \& L. Mourão. $O$ trabalho e as organizações: atuações a partir da Psicologia (pp. 225-278). Porto Alegre: Artmed.

Siqueira, D. M., \& Vieira, A. M. (2012). Valores Organizacionais: percepção e legitimação. Revista Gestão \& Tecnologia, 12(2), 168-191. 
Sina, A. (2007). A outra face do poder. São Paulo: Saraiva.

Smircich, L. (1983). Concepts of culture and organizational analysis. Administrative Science Quarterly, 28(3), 339-358.

Suxberger, A. H. G. (2009). O tamanho dos nossos sonhos: política e democracia no espaço entre nós e o contexto. In J. A. Dias, A. H. G. Suxberger, C. R. D. Garcia, \& R. R. Manente (Orgs.). O que fazer depois de passar em um concurso público (pp. 21-31). Blumenau: Nova Letra.

Tamayo, A. (1996). Valores organizacionais. In A. Tamayo, J. E. BorgesAndrade, \& W. Codo (Orgs.). Trabalho, Organizações e Cultura (pp. 175-193). São Paulo: Cooperativa de Autores Associados.

Tamayo, A. (2004). Cultura e saúde nas organizações. Porto Alegre: Artmed. Tamayo, A. (2006). Valores organizacionais e comprometimento afetivo. Revista de Administração Mackenzie, 6(3), 192-213.

Tamayo, A. (2007). Contribuições ao estudo dos valores pessoais, laborais e organizacionais. Psicologia: teoria e pesquisa, 23, 17-24.

Tamayo, A., \& Borges, L. O. (2006). Valores do trabalho e das organizações. In M. Ros, \& V. V. Gouveia (Orgs.). Psicologia social dos valores humanos: desenvolvimentos teóricos, metodológicos e aplicados (pp. 397-431). São Paulo: Editora Senac São Paulo.

Teixeira, M. L. M. (2008). Dignidade organizacional: valores e relações com stakeholders. In M. L. M. Teixeira (Org.). Valores humanos \& gestão: novas perspectivas (pp. 81-92). São Paulo: Editora Senac.

Tolfo, S. R., Silva, N., \& Krawulski, E. (2013). Acoso laboral: relaciones con la cultura organizacional y la gestión de personas. Salud de los Trabajadores, 21(1), 5-18.
Tolfo, S. R., Silva, N., \& Krawulski, E. (2015). Assédio Moral no Trabalho: interface com a cultura organizacional e gestão de pessoa em organizações públicas. In: M. L. Emmendoerfer, S. R. Tolfo, \& T. S. Nunes (Org.). Assédio Moral em organizações públicas e a (Re)Ação dos Sindicatos (pp. 99-118). 1. ed. Curitiba: CRV.

Triviños, A. N. S. (1992). Introdução à pesquisa em ciências sociais: a pesquisa qualitativa em educação. São Paulo: Atlas.

UFSC. Universidade Federal de Santa Catarina (2010). Plano de Desenvolvimento Institucional 2010 a 2014. Florianópolis: UFSC. Disponível em: <http://pdi.paginas.ufsc.br/files/2011/03/PDI-2010-2014.pdf>. Acesso em: 25 abr. 2014

UFSC. Universidade Federal de Santa Catarina (2014). UFSC EM NÚMEROS. Florianópolis: UFSC. Disponível em: <http://dpgi.proplan.ufsc.br/ufsc-em-numeros/>. Acesso em: 21 abr. 2015.

Vieira, M. S. O. C., \& Gomes, D. C. (2013). Valores organizacionais numa instituição pública de ensino do RN. HOLOS, 29(3), 77-89.

Vveinhardt, J., \& Gulbovaitè, E. (2015). Expert Evaluation of Diagnostic Instrument for Personal and Organizational Value Congruence. Journal of Business Ethics, 136(3), 481-501.

Zanelli, J. C., \& Silva, N. (2008). Interação humana e gestão: a construção psicossocial das organizações de trabalho. São Paulo: Casa do Psicólogo.

Zanini, M. T. (2007). Confiança: o principal ativo intangível de uma empresa. Rio de Janeiro: Elsevier.

Zanini, M. T. F., \& Migueles, C. P. (2014) O papel mediador entre confiança e desempenho organizacional. Revista de Administração, 49(1), 45-58. 